\title{
Extrusion Compounding Process for the Development of Eco-Friendly SCG/PP Composite Pellets
}

\author{
Joo Seong Sohn ${ }^{\circledR}$, Youngjae Ryu ${ }^{\circledR}$, Chang-Seok Yun, Kun Zhu and Sung Woon Cha * \\ School of Mechanical Engineering, Yonsei University, 50, Yonsei-ro, Seodaemun-gu, Seoul 03722, Korea; \\ ssamjjang87@yonsei.ac.kr (J.S.S.); yjryu1027@yonsei.ac.kr (Y.R.); changseok2614@yonsei.ac.kr (C.-S.Y.); \\ hknuuz@yonsei.ac.kr (K.Z.) \\ * Correspondence: swcha@yonsei.ac.kr; Tel.: +82-2-2123-7224
}

Received: 15 February 2019; Accepted: 16 March 2019; Published: 21 March 2019

\begin{abstract}
As the consumption of coffee increases worldwide, the amount of spent coffee grounds (SCG) is gradually increasing every year. Some of these grounds are recycled for composting, but most are discarded, which causes widespread financial and social costs. We developed a bio-based plastic pellet by blending polypropylene (PP) with waste biomass SCG to convert it into a sustainable, recyclable eco-friendly material. It was confirmed that extrusion compounding for SCG/PP composite pellets and injection molding with good formability are possible. To evaluate the formability of the composite pellets, American Society for Testing and Materials (ASTM) test specimens were prepared for evaluating mechanical properties by injection molding. As a result of the measurement of the test samples, the mechanical properties of SCG/PP composite pellets were generally lowered as the SCG content increased. However, the impact strength of SCG/PP composite based on the HOMO-PP matrix improved as the SCG content increased. In addition, Young's modulus of SCG/PP increased as the SCG content increased. In the future, this study will be applied to manufacture of products that requires non-toxic products, such as disposable products and food containers, realizing commercialization of eco-friendly products and thereby replacing finite petroleum resources and practicing resource circulation and environmental protection.
\end{abstract}

Keywords: spent coffee grounds; polypropylene; composites; extrusion compounding process; injection molding process; mechanical properties

\section{Introduction}

Most common household items around us are made of plastic, which provides a lot of convenience in our lives. However, since most conventional plastics are manufactured as disposable products, they are not easily decomposed at the time of disposal, thereby causing environmental pollution and health risk problems [1,2].

Since oil reserves in the earth are slowly depleting, it is necessary to reduce the use of petroleum resources and develop alternative materials. In the long term, reducing the amount of plastics used is an appropriate and practical method for reducing use of such resources. However, considering the current industrial structures, such as production facilities, and demand in the market, it is almost impossible to immediately stop using plastic materials. Therefore, we propose a realistic solution to reduce the amount of plastic used, until the development of complete technology that does not use plastic materials and the establishment of an improved industrial environment in the future.

In recent years, as the quality of life has improved and global environmental regulations have emerged, there has been an increasing interest in environmentally friendly plastics to reduce emission of carbon dioxide and to work toward carbon neutrality for green growth [3,4]. Many countries around 
the world are actively pursuing research and technology development regarding environmentally friendly bioplastics, and are preparing relevant laws and regulations.

Some of them are trying to increase the decomposition rate by reducing the amount of plastic and by manufacturing bioplastics which are composite materials, including biomass from organic waste resources [5,6]. As a concept of a quantitative biological resource, biomass is a renewable organic resource. Examples of this include agricultural products such as sugar cane and starch, forest products such as cellulose, microorganisms such as chlorella and spirulina, and whale oil. In other words, all organisms are examples of biomass [7]. The total amount of biomass globally produced in one year is similar to the total amount of petroleum produced, so it has the advantage of not being exhausted if used appropriately $[8,9]$. A typical biomass material that has been in commercial use is wood. Many studies have been carried out for manufacturing wood polymer composites by combining polymer with wood [10-12]. In addition, studies on the addition of fly ash, which is generated in the process of burning coal, to polymers have also been conducted [13-15].

From this viewpoint, we selected spent coffee grounds (SCG) as biomass and developed bio-based plastic with an SCG content of more than $25 \%$ by an extrusion and injection molding process. The manufacturing of SCG composites has been studied [16-19]. Chitra et al. analyzed the mechanical properties of SCG/PP by incorporating 15\% SCG into PP as a function of compatibilizer content by extrusion and injection molding [16]. García-García et al. have found a difference in mechanical properties of SCG/PP between the chemically pretreated SCG and the untreated SCG, when SCG is added to PP at $20 \mathrm{wt} \%$ [17]. Essabir et al. identified the thermal, rheological, and mechanical properties of SCG/PP composites as a function of SCG content (0 20 wt \%) [19]. Although many studies have been made on polymer composites with SCG, it has been difficult to satisfy the criteria for being a bio-based plastic because its content is $20-25 \mathrm{wt} \%$ or less in extrusion and injection molding process. Polymer composites, including biomass, can only be recognized as a bio-based plastic if the biomass content exceeds 20-25 wt \% (more than 20\% in Europe, more than 25\% in the United States, Japan, and Korea) [20-22]. Our study is expected to provide a new recycling method for SCG.

As a foodstuff, coffee has a high weekly consumption rate per person. In addition, annual coffee imports and coffee shops are on the increase, and the amount of SCG is also increasing. SCG is classified as general waste and some is composted, but it is hardly utilized compared to the amount of waste generated. This is because public awareness and interest in the recycling of SCG are not high. Only around $0.2 \%$ of coffee beans are used to make coffee, and about $99.8 \%$ are discarded [23]. According to data from the International Coffee Organization, annual global coffee consumption has grown to more than 100 million bags $(1 \mathrm{bag}=60 \mathrm{~kg}$ ) in recent years, and consumption is steadily increasing as the coffee consumption population increases [24]. According to the report, by 2017, Korea had become the seventh largest importer of coffee in the world. In Finland, the country with the highest coffee consumption, people consume $12.5 \mathrm{~kg}$ of coffee per year on average. According to the data from Statistics Korea (KOSTAT, Korea), as of 2014, around 270,000 tons of SCG were found in sewage treatment plants [25]. SCG generates 50,490 tons of carbon dioxide per year and causes environmental pollution. The cost of disposing of this waste is around $\$ 29$ million, and the economic loss, including labor costs, is around $\$ 680$ million.

To solve the social disposal cost of SCG and to propose a new recycling plan, this study examined the possibility of recycling SCG by developing eco-friendly bio-based high value-added plastic composite pellets $[26,27]$. Bio-based plastics based on SCG can be recycled repeatedly after use, and can be lightweight, save on manufacturing costs, and replace finite petroleum resources. Therefore, resource circulation and environmental protection can be practiced. 


\section{Materials and Methods}

\subsection{Materials}

HPP (HOMO-polypropylene, Lotte Chemical Corp., Grade No. J150, melting point-160 ${ }^{\circ} \mathrm{C}$, density-0.9 g/ $\mathrm{cm}^{3}$, Seoul, Korea) and BPP (BLOCK-polypropylene, Lotte Chemical Corp., Grade No. J350, melting point $-160{ }^{\circ} \mathrm{C}$, density $-0.9 \mathrm{~g} / \mathrm{cm}^{3}$, Seoul, Korea) were selected as the matrix of this study and the SCG biomass was supplied from a coffee shop chain (Cafe Sharing, ANYONE F\&C Co., Ltd., Seoul, Korea). The coffee beans were four varieties of Latin American beans, and the elapsed time after roasting was within about two weeks (Table 1). The SCG were collected and dried at $90^{\circ} \mathrm{C}$ for $12 \mathrm{~h}$ in a drier to remove moisture. Since SCG has a high water content after coffee extraction, mold can grow if it is not dried properly. PP, a hydrophobic thermoplastic matrix, and SCG, a hydrophilic natural material, were not compatible with each other. Therefore, compatibilizer was added to improve the compatibility and interfacial adhesion between SCG and PP matrix. For compatibilizer, MAPP (malleated polypropylene, Lotte Chemical Corp., Grade No. CM-1120W, Seoul, Korea) was added by $3 \mathrm{phr}$ in the extrusion compounding process.

Table 1. The proportion of spent coffee grounds (SCG) collected in this study.

\begin{tabular}{ccccc}
\hline Coffee Bean Varieties & Tarrazu & Antigua & Santos & Medellin \\
\hline Country of origin & Costa Rica & Guatemala & Brazil & Colombia \\
Mixing ratio $(\%)$ & 20 & 30 & 20 & 30 \\
\hline
\end{tabular}

\subsection{Particle Size Classification Method of SCG}

The SCG collected in this study are residual wastes remaining after coffee beans are pulverized by a grinder (Super Jolly Electronic, MAZZER corp., Venezia, Italy). However, since the particle size of the coffee bean was not easy to control given that the beans were ground in the coffee shop, we attempted to single them out for uniform particle sizes. Uneven particle size adversely affects the physical properties of the composite or final product, so the particle size must be checked and should be uniformly controlled beforehand if necessary. Classification of the particle size was carried out using a sieve test machine for $450 \mathrm{~g}$ of SCG, which shook the SCG for $300 \mathrm{~s}$ using a reciprocating speed of 120 times per minute. The machine was made by our own laboratory, and the test sieve (ChunggyeSieve Inc., Seoul, Korea) was purchased and fitted in the sieve test machine. The detailed specification is shown in Figure 1 and Table 2. Sieves were arranged in a stack with the mesh number in descending order from top to bottom. SCG clusters, which are clustered by residual moisture in $450 \mathrm{~g}$ of SCG, accounted for $4.4 \%$ (20 g) of the total amount. The particle size of 50 mesh was $36 \mathrm{~g}$, which accounted for $8 \%$ of the total, and the SCG corresponding to a particle size of 60 mesh was $4 \mathrm{~g}$, which was only $0.9 \%$ of the total. The average particle size of SCG was judged to be mainly in the range of 30 to 40 mesh. SCG cluster, 50 and 60 mesh, which accounted for a relatively small proportion, were excluded. Furthermore, the SCG cluster is likely to cause carbonization when it is discharged from a nozzle during high-temperature, high-pressure extrusion and injection processes. Therefore, the particle size of SCG selected in this study was in the range of 300-600 $\mu \mathrm{m}$ (Table 3 and Figure 2).

Table 2. Specification of sieve used in this study.

\begin{tabular}{cc}
\hline \multicolumn{2}{c}{ Vibratory Sieve Shaker } \\
\hline Number of mounted test sieves & 7 \\
Test sieve size $(\mathrm{mm})$ & $210(\Phi) \times 60(\mathrm{~h})$ \\
Motor & AC220 V, 60 Hz, $1 / 2 \mathrm{HP}$ \\
Operating method & Shaking left and right \\
\hline
\end{tabular}



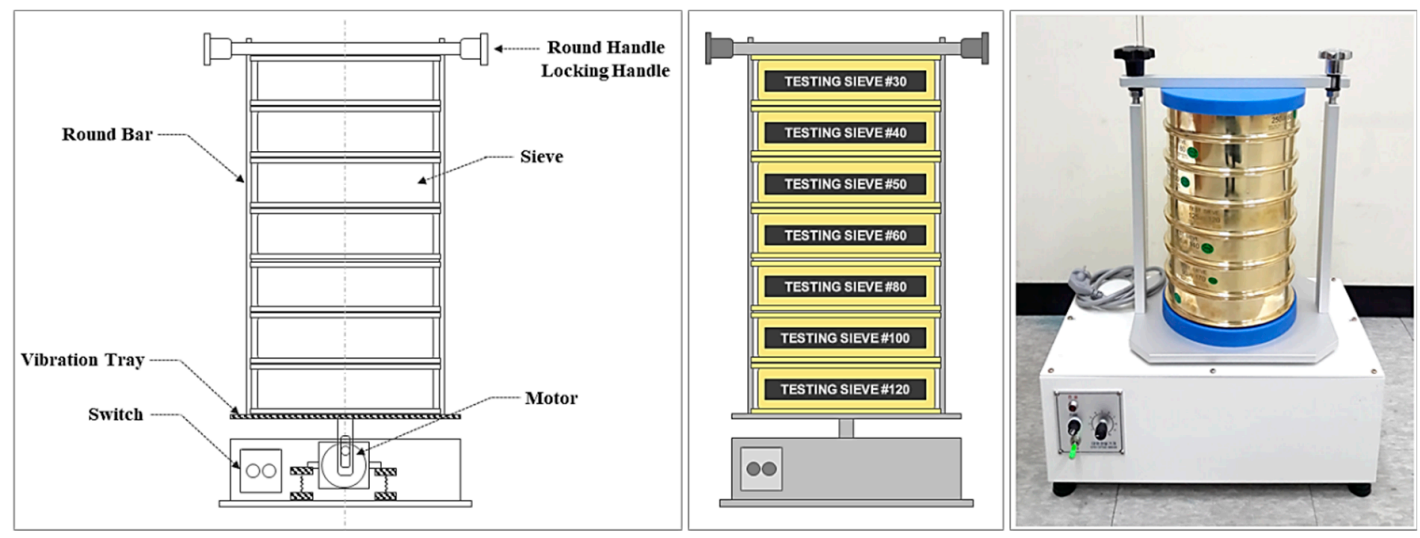

Figure 1. Sieve test machine designed and used in this study.

Table 3. Particle size distribution of collected SCG.

\begin{tabular}{cccccc}
\hline \multicolumn{5}{c}{ Classification of Particle Size for Collected SCG } \\
\hline Mesh number ${ }^{1}$ & Cluster & 30 & 40 & 50 & 60 \\
Particle size $(\mu \mathrm{m})$ & Unknown & 600 & 425 & 300 & 250 \\
Amounts $^{2}(\mathrm{~g})$ & $20 \mathrm{~g}$ & $182 \mathrm{~g}( \pm 21.0)$ & $208 \mathrm{~g}( \pm 16.0)$ & $36 \mathrm{~g}( \pm 5.2)$ & $4 \mathrm{~g}( \pm 3.2)$ \\
Ratio $(\%)$ & 4.4 & 40.4 & 46.2 & 8.0 & 4 \\
\hline
\end{tabular}

${ }^{1}$ Sieve mesh chart for mesh number according to particle size based on ASTM E 11-70; ${ }^{2}$ Sieve test for $450 \mathrm{~g}$ of collected SCG.
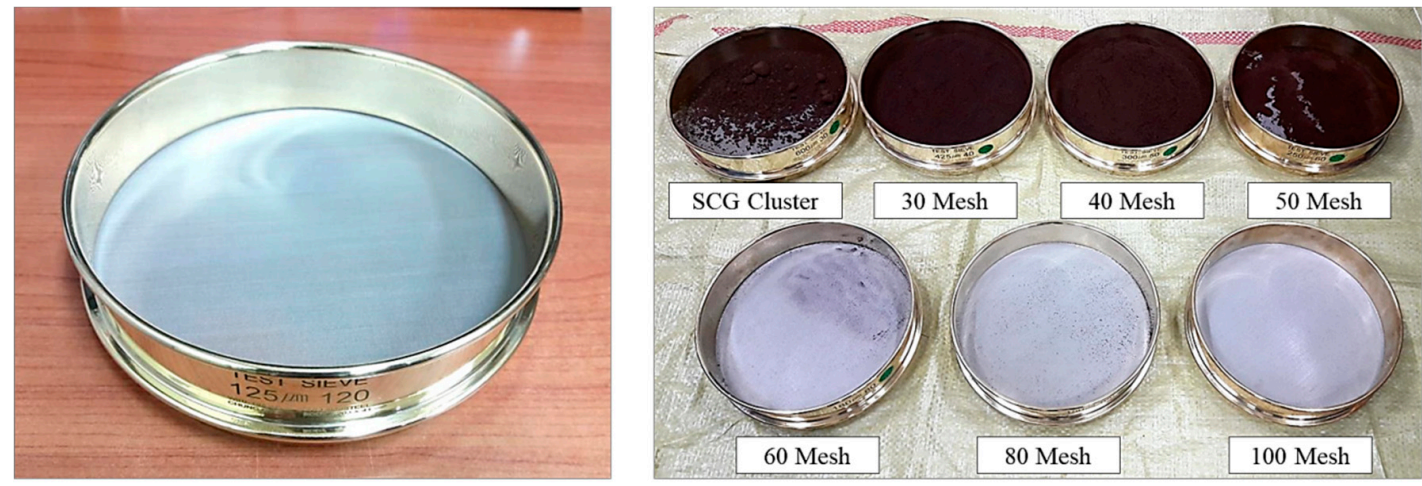

Figure 2. Results of classification experiments according to particle size of SCG collected by sieve shaker.

\subsection{Extrusion Compounding Process}

Two types of matrix, HOMO-PP and BLOCK-PP, were used and compounding was performed for SCG-PP composite material. PP and SCG were mixed in a weight ratio of 100/0, 90/10, 80/20, and 70/30 using an extruder (Yonsei University, Korea), and the mixture was poured into an extruder hopper to form a composite material pellet (Figure 3). The screw was set at $120 \mathrm{rpm}$ during the extrusion compounding process. This is because, when compounding different kinds of materials, it is desirable to have a high torque at a low speed for stable discharge, but too low a discharge speed lowers productivity. The heater temperature of the extruder was set at $200{ }^{\circ} \mathrm{C}$. At lower temperatures, feeding the material into the extruder barrel was difficult and the compounding did not work well. Above $130{ }^{\circ} \mathrm{C}$, it was found that the temperature at which the discharge is performed while increasing the molding temperature was smoothly transferred at the reference temperature of $200{ }^{\circ} \mathrm{C}$ (Table 4). Temperatures of $200^{\circ} \mathrm{C}$ or higher were not considered or confirmed through experiments. As a biomass, SCG, which is a natural material, can suffer from carbonization or clogging due to caramelization of residual saccharides. The compounding die was set in a circle shape with a diameter of $\Phi 3 \mathrm{~mm}$, to be formed into the actual pellet. In the cooling process, a cooling line was installed by the air-cooling type, and a cutting device capable of cutting the pellet to a certain size was connected at the end of 
the cooling line (Figure 4). Conventional compounding processes are mostly water-cooled lines for rapid cooling. However, in the case of SCG, because it is highly hygroscopic compared to a general hydrophobic plastic material, it was considered that it would be advantageous to block moisture, so the air-cooling method was selected.

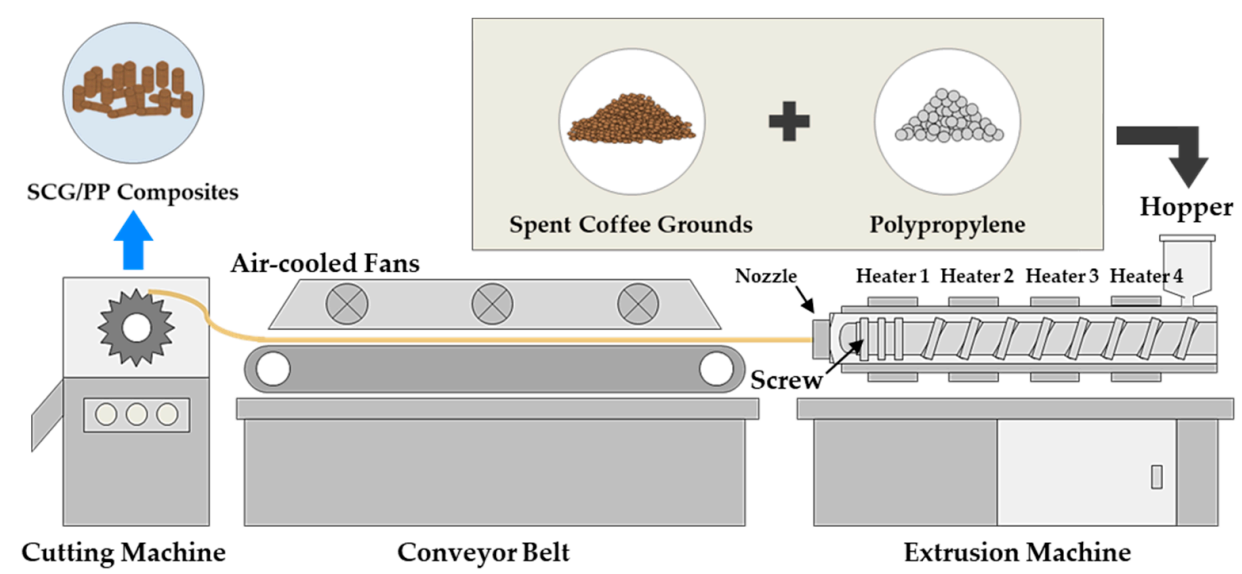

Figure 3. Schematic of extrusion compounding process.

Table 4. Experimental conditions of compounding pelletization process using extruder.

\begin{tabular}{|c|c|c|c|c|}
\hline Material & Spent Coffee Grounds & & Polypropylene & \\
\hline Mixing ratio (\%) & $0 / 10 / 20 / 30$ & & $100 / 90 / 80 / 70$ & \\
\hline Compatibilizer (phr) & & 3 & & \\
\hline Die diameter $(\phi)$ & & 3 & & \\
\hline Motor RPM & & 1800 & & \\
\hline Screw RPM & & 120 & & \\
\hline \multirow{2}{*}{ Temperature $\left({ }^{\circ} \mathrm{C}\right)$} & $\mathrm{NZ}$ & $\mathrm{H} 2$ & $\mathrm{H} 3$ & $\mathrm{H} 4$ \\
\hline & 200 & 180 & 160 & 140 \\
\hline
\end{tabular}
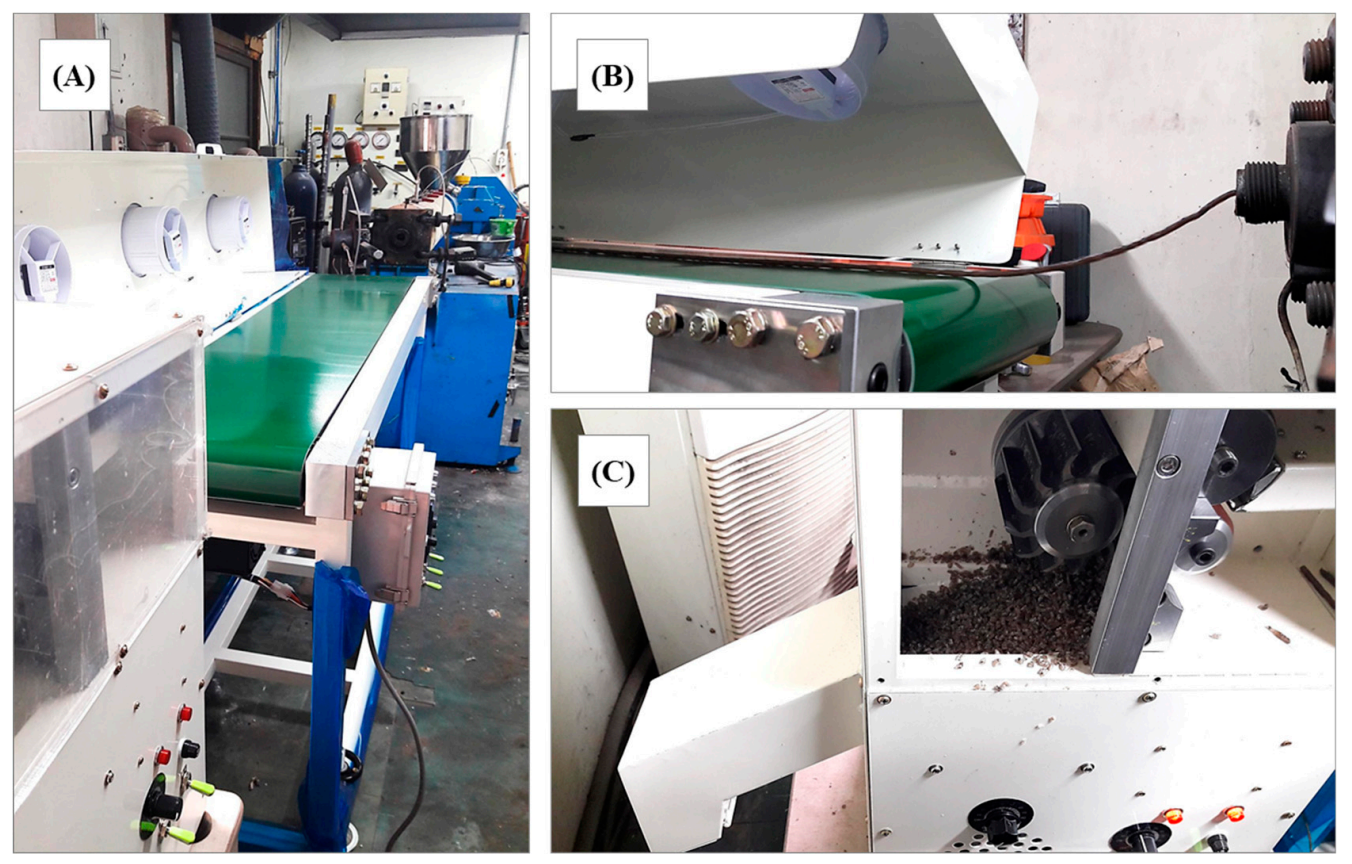

Figure 4. Processes of extrusion compounding experiments for pelletization: (A) Extruders, conveyors and cutting machine for forming SCG-PP composite pellets. (B) Process for transferring extruded molten SCG-PP composites using air-cooled conveyor belts. (C) Cutting process for pelletizing cooled SCG-PP extruded strands. 


\subsection{Injection Molding Process}

An injection molding process (Figure 5) was carried out to evaluate the mechanical properties of SCG-PP composite pellets formed by varying the content of SCG based on the HOMO-PP and BLOCK-PP matrix. The screw mounted on an injection molding machine (WOOJIN SELEX Corp., Product No. E-120) has an L/D of 28:1, and a clamping force of 120 tons. American Society for Testing and Materials (ASTM) standard molds were used to measure mechanical properties. The temperature of the process was controlled to $200{ }^{\circ} \mathrm{C}$ or less to prevent carbonization of SCG. The conditions of the injection molding process are detailed in Table 5. Injection-molded specimens of Neat-PP and SCG-PP composites are shown in Figure 6.

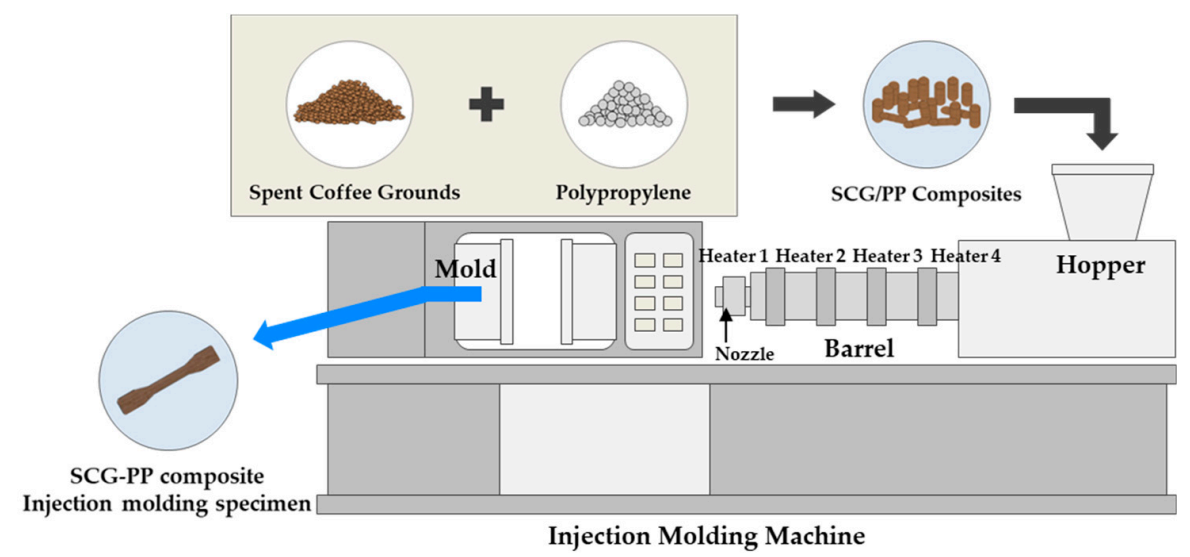

Figure 5. Schematic of SCG-PP composite injection molding specimen preparation.

Table 5. Experimental conditions of injection molding machine for confirmation of formability of SCG-PP composite pellets.

\begin{tabular}{cccccc}
\hline \multicolumn{6}{c}{ Experimental Condition of Injection Molding Machine } \\
\hline Injection temp. $\left({ }^{\circ} \mathrm{C}\right)$ & $\mathrm{NZ}$ & $\mathrm{H} 1$ & $\mathrm{H} 2$ & $\mathrm{H} 3$ & $\mathrm{H} 4$ \\
Injection press. (MPa) & 200 & 190 & 180 & 170 & 165 \\
Holding press. (MPa) & & & 5 & & \\
Holding time (s) & & & 3 & & \\
Cooling time (s) & & & 15 & & \\
\hline
\end{tabular}

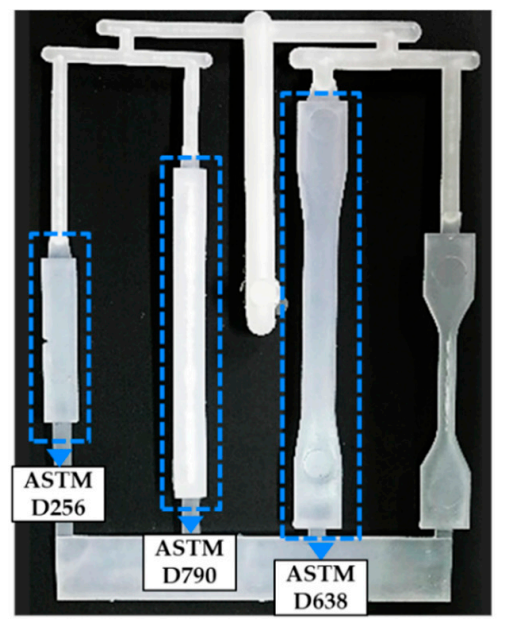

(A)

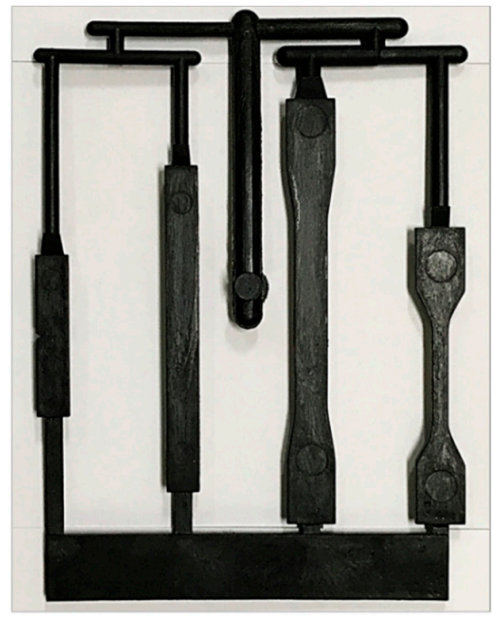

(B)

Figure 6. ASTM standard injection molding specimens for measuring mechanical properties: (A) Neat HOMO-PP; (B) SCG30/PP70 composite. 


\subsection{Method of Measuring Mechanical Properties}

Formability evaluation of SCG/PP composite pellets was carried out by ASTM specimens using the injection molding process (Figure 6) and mechanical properties were measured. The impact strength (ASTM D256) was measured using a digital impact tester (Salt Co. Ltd., Model No. ST-120, Incheon, Korea) and the tensile strength (ASTM D638) and flexural modulus (ASTM D790) were measured using UTM (Universal Testing Machine, QMESYS Co. Ltd., Model No. QM-100T, Seoul, Korea). Impact strength was measured in accordance with the ASTM D 256 method, and the specimen sizes were $63.5 \times 12.7 \times 3.0 \mathrm{~mm}^{3}$. The impact was applied to the side of the notch [28]. The tensile strength was measured in accordance with the ASTM D 638 method, and the specimen sizes were $165 \times 19 \times 3.3 \mathrm{~mm}^{3}$. The cross-head speed was $10 \mathrm{~mm} / \mathrm{min}$ when measuring the tensile strength [29]. The flexural modulus was measured in accordance with the ASTM D 790 method, and the specimen sizes were $127 \times 12.7 \times 6.4 \mathrm{~mm}^{3}$. The support distance of specimens was $102.4 \mathrm{~mm}$ and the test load speed was $10 \mathrm{~mm} / \mathrm{min}$ [30]. The mechanical properties values were obtained by averaging the measured values of five specimens.

\section{Results and Discussion}

For the evaluation of the formability of SCG-PP composite pellets, the mechanical properties of ASTM injection-molded specimens were measured. Using HOMO-PP and BLOCK-PP as a matrix, the content of SCG was increased to $10 \%, 20 \%$, and $30 \%$ by weight to meet the biomass content of $25 \%$. The amount of MAPP added to improve compatibility between hydrophilic SCG and hydrophobic PP was 3 phr. MAPP is an additive that helps disperse SCG uniformly in the PP matrix, and it improves the disadvantage of mechanical properties due to poor compatibility between plastic polymer resin and the biomass SCG.

The results of the measurement (Figure 7) of the impact strength indicated that the mechanical properties of the composite pellets based on the matrix HOMO-PP and BLOCK-PP were opposite. This result is caused by the difference in structure between HOMO-PP and BLOCK-PP [31]. HOMO-PP is a polymer polymerized with propylene alone, so it has high regularity and crystallinity. On the other hand, BLOCK-PP has lower crystallinity than HOMO-PP because of the ethylene polymerized into the arrangement of propylene.

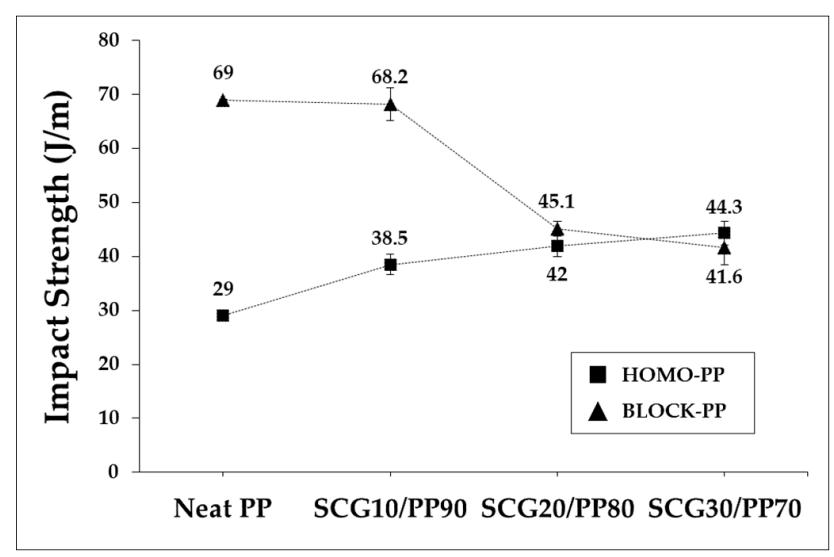

Figure 7. Results of impact strength measurement of composite pellets according to the mixing ratios of SCG and PP.

In the case of HOMO-PP, the impact strength increased as the content of SCG was increased; the maximum value was increased by $52.8 \%$ when the SCG content was $30 \%$. The increase in impact strength of SCG/HOMO-PP was the first reported result, and is expected to be applicable to eco-friendly materials for food containers and small household appliances that require impact resistance. SCG decrease the crystallinity of HOMO-PP and increase the amorphous region, thereby minimizing brittleness and increasing the impact strength of HOMO-PP. 
On the other hand, the impact strength of BLOCK-PP decreased by $39.7 \%$ as the SCG content increased when the SCG content was 30\%. The tendency of the reduced impact strength of BLOCK-PP is the same as in a previous study [17]. This is related to the copolymer type of BLOCK-PP. When the content of SCG is low, the impact strength hardly decreases. However, since BLOCK-PP has a low crystallinity compared to HOMO-PP, it is difficult to dramatically increase the amorphous region by incorporating SCG into BLOCK-PP, and increasing the impact strength of BLOCK-PP is expected to be hard.

The results of tensile strength measurements (Figure 8) indicated that tensile strength values decreased when SCG was mixed with neat HOMO-PP and neat BLOCK-PP. These results are similar to those of previous studies [19]. It is considered that the added SCG does not act as a reinforcing material and acts as a micro-defect in the composites that reduces the tensile strength of the specimen. In addition, as the SCG increases content, phase separation with the matrix occurs and it is considered to cause a decrease in tensile strength as an interface defect occurs [32].

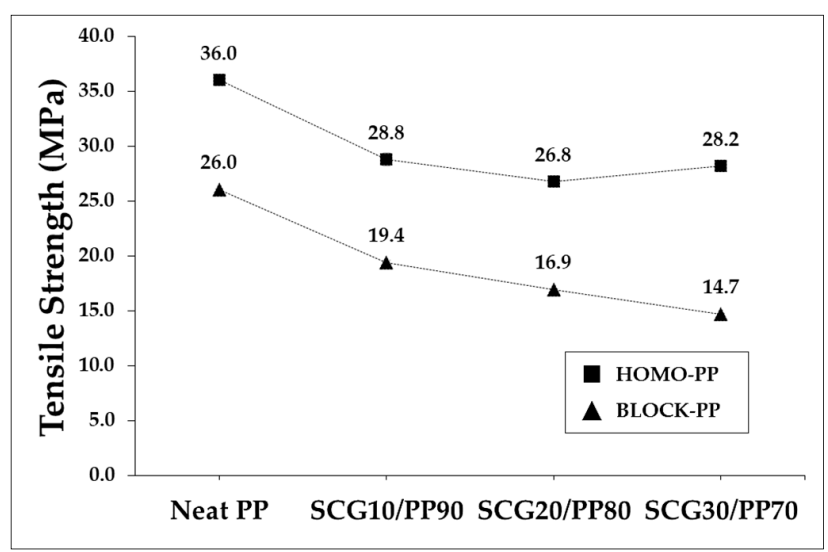

Figure 8. Results of tensile strength measurement of composite pellets according to the mixing ratios of SCG and PP.

The flexural modulus (Figure 9) also showed a tendency to decrease when SCG was mixed and showed the highest value at $20-30 \%$ of SCG content among SCG/PP. However, the flexural modulus of the SCG/BLOCK-PP is not significantly different from Neat-PP (only $1.5 \%$ reduction at SCG30/BLOCK-PP compared to Neat-PP). Based on the results of the mechanical properties measurement, the particles of SCG were not considered to act as a reinforcing agent, and acted as a filler. The main constituents of SCG (g/100 g) are hemicellulose ( $36.7 \mathrm{~g})$, mannose $(21.2 \mathrm{~g})$, galactose $(13.8 \mathrm{~g})$, protein (13.6 g), and glucose (8.6 g) [33]. Therefore, residual proteins in SCG may be the reason for decreased flexural modulus.

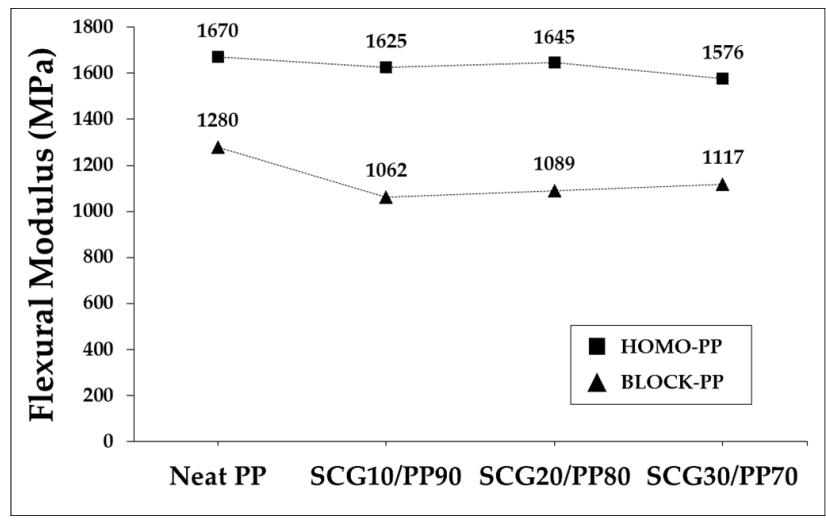

Figure 9. Results of flexural modulus measurement of composite pellets according to the mixing ratios of SCG and PP. 
Figures 10 and 11 shows flexural strength and Young's modulus of SCG/PP. Flexural strength decreased with the addition of SCG as flexural modulus. However, the Young's modulus increased with the addition of SCG. The increased Young's modulus of SCG/PP is analyzed to be due to the intrinsic rigidity of SCG [19]. The higher the Young's modulus, the more excellent the stiffness, so that this tendency can be applied to the manufacture of automotive interior materials which require environment friendliness and high stiffness.

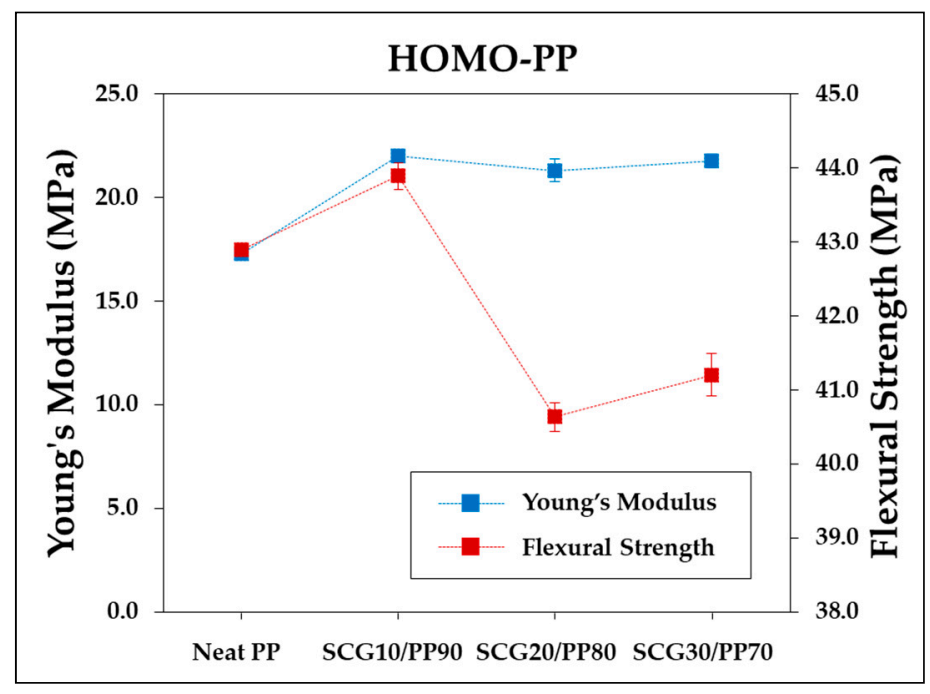

Figure 10. Results of flexural strength and Young's modulus measurement of composite pellets according to the mixing ratios of SCG and HOMO-PP.

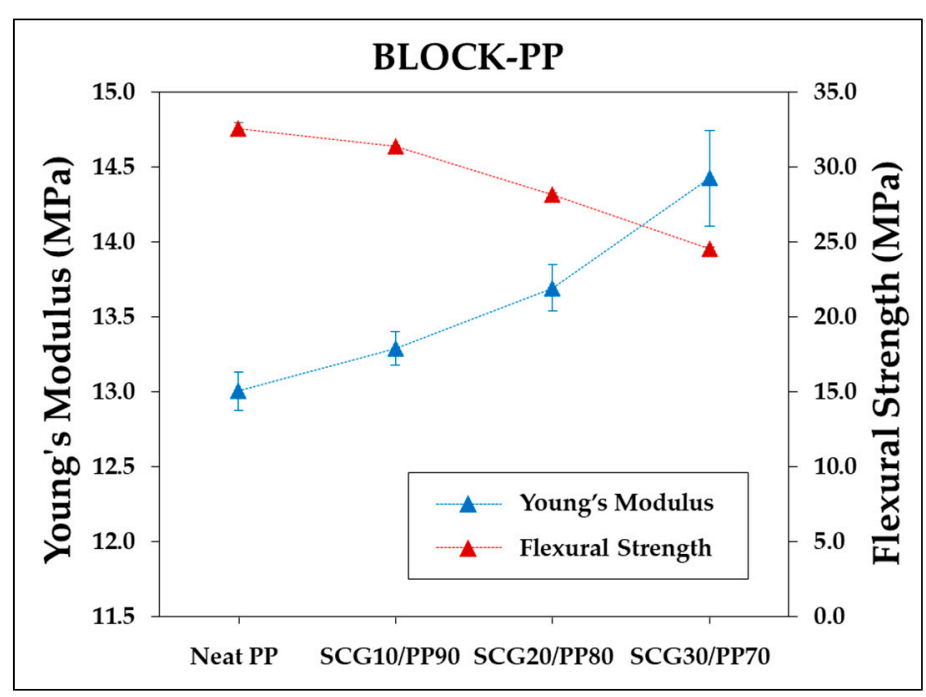

Figure 11. Results of flexural strength and Young's modulus measurement of composite pellets according to the mixing ratios of SCG and BLOCK-PP.

In addition, scanning electron microscope (JEOL Ltd., Product No. 7001F, Tokyo, Japan) observations were performed to investigate the morphology of the SCG particles. The cross-sectioned test specimen for impact strength was frozen in liquefied nitrogen, fractured, and then measured. It was confirmed that the SCG particles were combined with PP matrix (Figure 12). SCG is sieved with a size of 300-600 $\mu \mathrm{m}$, but since the SCG form clusters, the size of each individual SCG particle is analyzed to be smaller, such as $10-20 \mu \mathrm{m}$, which is similar to previous studies [17,18]. 

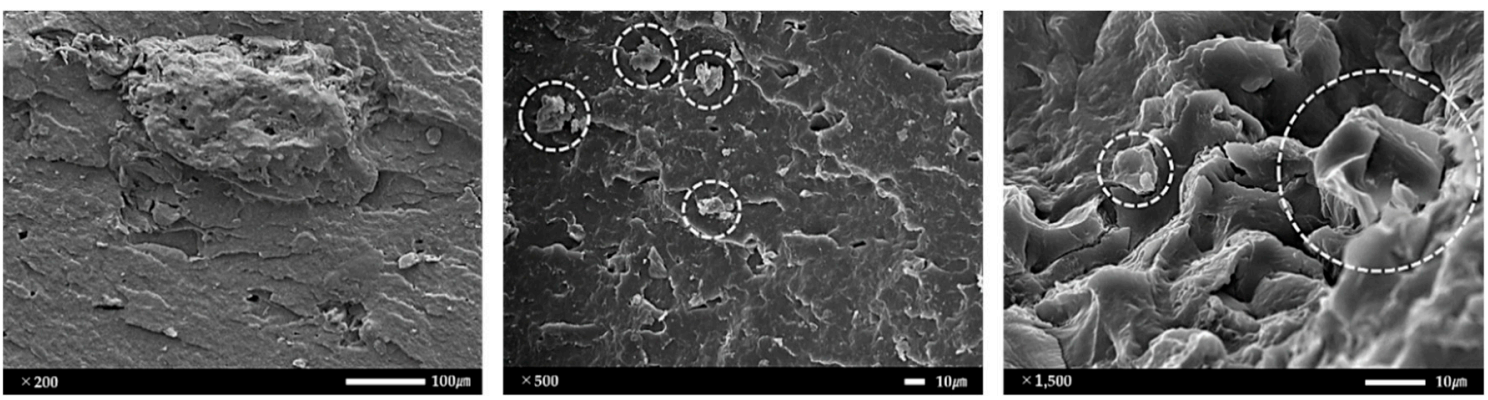

Figure 12. SCG particles in PP matrix under mixed conditions of SCG30/PP70.

\section{Conclusions}

In this study, SCG/PP composite pellets were prepared through an extrusion compounding process to explore the material recycling method of SCG, a waste biomass, and to develop sustainable environmentally friendly materials. ASTM standard injection-molded specimens were prepared for the evaluation of formability, and evaluation of mechanical properties was performed. The extrusion compounding process for the composite pellets of SCG-PP and the injection molding process for the test specimens of mechanical properties were confirmed to have good formability. SCG in composite materials met the standard for being a bio-based plastic, containing up to $30 \%$ by weight. The measurement of mechanical properties showed that the mechanical property values were generally lowered as the content of SCG increased. Since the hydrophilic SCG and hydrophobic PP are different materials, it is considered that the interfacial adhesion is poor, and is considered to be a key factor in lowering the mechanical properties due to phase separation. Therefore, further research is being conducted on the necessary modification of the surface of SCG. However, it was confirmed that the impact strength of neat HOMO-PP and Young's modulus of PP are increased as the content of SCG increased. These results can be applied to food containers, small household appliances, and automotive interior products requiring high impact strength, high stiffness, and environmentally friendly regulations. Disposable biomass, such as SCG, is glucose-based cellulose, so it is harmless to the human body and can be used as an environmentally friendly sensitive material. The SCG-PP composite material pellet is expected to be widely applicable to real-life applications if it can be applied to non-toxic products, such as disposable products and food containers.

Author Contributions: J.S.S. conceived and designed the experiments; C.-S.Y. and K.Z. performed the experiments; J.S.S. and Y.R. analyzed the data; S.W.C. funding acquisition; J.S.S. review and editing, J.S.S. wrote the paper.

Funding: This research was supported by Basic Science Research Program through the National Research Foundation of Korea (NRF) funded by the Ministry of Education (No. NRF-2018R1D1A1B07049405).

Acknowledgments: The first author would like to thank Sung Woon Cha for their advice and guidance.

Conflicts of Interest: The authors declare no conflicts of interest.

\section{References}

1. Koch, H.M.; Calafat, A.M. Human body burdens of chemicals used in plastic manufacture. Philos. Trans. R. Soc. B Biol. Sci. 2009, 364, 2063-2078. [CrossRef] [PubMed]

2. Halden, R.U. Plastics and Health Risks. Annu. Rev. Public Health 2010, 31, 179-194. [CrossRef] [PubMed]

3. Rau, C. Supporting carbon neutrality in urban environments using positive energy buildings. Int. J. Sustain. Dev. Plan. 2017, 12, 580-588. [CrossRef]

4. Dahal, K.; Juhola, S.; Niemelä, J. The role of renewable energy policies for carbon neutrality in Helsinki Metropolitan area. Sustain. Cities Soc. 2018, 40, 222-232. [CrossRef]

5. Cho, D.; Kim, H.J. Naturally Cyclable Bio-composites. Elast. Compos. 2009, 44, 13.

6. Arbelaiz, A.; Fernandez, B.; Ramos, J.A.; Retegi, A.; Llano-Ponte, R.; Mondragon, I. Mechanical properties of short flax fibre bundle/polypropylene composites: Influence of matrix/fibre modification, fibre content, water uptake and recycling. Compos. Sci. Technol. 2005, 65, 1582-1592. [CrossRef] 
7. Rosillo-Calle, F. A review of biomass energy - shortcomings and concerns. J. Chem. Technol. Biotechnol. 2016, 91, 1933-1945. [CrossRef]

8. Field, C.B.; Behrenfeld, M.J.; Randerson, J.T.; Falkowski, P. Primary production of the biosphere: Integrating terrestrial and oceanic components. Science 1998, 281, 237-240. [CrossRef]

9. Statistical Review of World Energy. Available online: https://www.bp.com/en/global/corporate/energyeconomics/statistical-review-of-world-energy.html (accessed on 14 February 2019).

10. Porebska, R.; Rybak, A.; Kozub, B.; Sekula, R. Polymer matrix influence on stability of wood polymer composites. Polym. Adv. Technol. 2015, 26, 1076-1082. [CrossRef]

11. Sohn, J.S.; Cha, S.W. Enhanced interfacial adhesion of polypropylene and waste wood from roadside trees composite materials. Int. J. Precis. Eng. Manuf. 2015, 16, 2389-2393. [CrossRef]

12. Sohn, J.S.; Cha, S.W. Effect of chemical modification on mechanical properties of wood-plastic composite injection-molded parts. Polymers 2018, 10, 1391. [CrossRef]

13. Parvaiz, M.R.; Mahanwar, P.A.; Mohanty, S.; Nayak, S.K. Effect of surface modification of fly ash reinforced in polyetheretherketone composites. Polym. Compos. 2011, 32, 1115-1124. [CrossRef]

14. Sroka, J.; Rybak, A.; Sekula, R.; Sitarz, M. An Investigation into the Influence of Filler Silanization Conditions on Mechanical and Thermal Parameters of Epoxy Resin-Fly Ash Composites. J. Polym. Environ. 2016, 24, 298-308. [CrossRef]

15. Sroka, J.; Rybak, A.; Sekula, R.; Filipczak, P.; Kozanecki, M.; Sitarz, M. Two-Step Procedure of Fly Ash Modification as an Alternative Method for Creation of Functional Composite. J. Polym. Environ. 2017, 25, 1342-1347. [CrossRef]

16. Chitra, N.J.; Vasanthakumari, R.; Amanulla, S. Preliminary Studies of the Effect of Coupling Agent on the Properties of Spent Coffee Grounds Polypropylene Bio-Composites. Int. J. Eng. Res. Technol. 2014, 7, 9-16.

17. García-García, D.; Carbonell, A.; Samper, M.D.; García-Sanoguera, D.; Balart, R. Green composites based on polypropylene matrix and hydrophobized spend coffee ground (SCG) powder. Compos. Part B Eng. 2015, 78, 256-265. [CrossRef]

18. Zarrinbakhsh, N.; Wang, T.; Rodriguez-Uribe, A.; Misra, M.; Mohanty, A.K. Characterization of wastes and coproducts from the coffee industry for composite material production. BioResources 2016, 11, 7637-7653. [CrossRef]

19. Essabir, H.; Raji, M.; Laaziz, S.A.; Rodrique, D.; Bouhfid, R.; Qaiss, A.E.K. Thermo-mechanical performances of polypropylene biocomposites based on untreated, treated and compatibilized spent coffee grounds. Compos. Part B Eng 2018, 149, 1-11. [CrossRef]

20. Iwata, T. Biodegradable and bio-based polymers: Future prospects of eco-friendly plastics. Angew. Chem. Int. Ed. 2015, 54, 3210-3215. [CrossRef]

21. Spierling, S.; Knüpffer, E.; Behnsen, H.; Mudersbach, M.; Krieg, H.; Springer, S.; Albrecht, S.; Herrmann, C.; Endres, H.J. Bio-based plastics-A review of environmental, social and economic impact assessments. J. Clean. Prod. 2018, 185, 476-491. [CrossRef]

22. You, Y.S. Korea Bio Material Packaging Association. BioMagazine 2018, 10, 1801.

23. Pauli, G. The Blue Economy 3.0: The Marriage of Science, Innovation and Entrepreneurship Creates a New Business Model That Transforms Society; Xlibris Corporation: Bloomington, IN, USA, 2017; p. 288.

24. Annual Global Coffee Consumption Data. Available online: https://www.ico.org (accessed on 7 March 2019).

25. Spent Coffee Grounds in Korea. Available online: http:/ / kostat.go.kr (accessed on 7 March 2019).

26. Kondamudi, N.; Mohapatra, S.K.; Misra, M. Spent coffee grounds as a versatile source of green energy. J. Agric. Food Chem. 2008, 56, 11757-11760. [CrossRef] [PubMed]

27. Panusa, A.; Zuorro, A.; Lavecchia, R.; Marrosu, G.; Petrucci, R. Recovery of natural antioxidants from spent coffee grounds. J. Agric. Food Chem. 2013, 61, 4162-4168. [CrossRef] [PubMed]

28. ASTM Standard D256. Standard Test Methods for Determining the Izod Pendulum Impact Resistance of Plastics; ASTM International: West Conshohocken, PA, USA, 2016.

29. ASTM Standard D638. Standard Test Method for Tensile Properties of Plastics; ASTM International: West Conshohocken, PA, USA, 2016.

30. ASTM Standard D790. Standard Test Methods for Flexural Properties of Unreinforced and Reinforced Plastics and Electrical Insulating Materials; ASTM International: West Conshohocken, PA, USA, 2016. 
31. Karger-Kocsis, J. Polypropylene: Structure, Blends and Composites-Structure and Morphology; Chapman and Hall: Boca Raton, FL, USA, 1995; Volume 1, p. 351.

32. Lee, K.H.; Byon, S. A Study on the Phase Separation and Mechanical Properties of Wood Flour-Polypropylene Composites. Elastom. Compos. 2013, 48, 216-220. [CrossRef]

33. Mussatto, S.I.; Machado, E.M.S.; Martins, S.; Teixeira, J.A. Production, Composition, and Application of Coffee and Its Industrial Residues. Food Bioprocess Technol. 2011, 4, 661-672. [CrossRef]

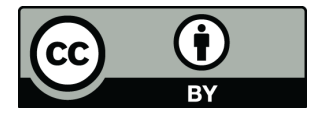

(c) 2019 by the authors. Licensee MDPI, Basel, Switzerland. This article is an open access article distributed under the terms and conditions of the Creative Commons Attribution (CC BY) license (http:/ / creativecommons.org/licenses/by/4.0/). 